\title{
MAROTO, MANOTERA, SALMERONN: APORTACIONES DE TOPONIMIA ESPAÑOLA A PROPÓSITO DE LA EXPRESIÓN DE LOMA
}

\author{
E. Nieto Ballester \\ Universidad Autónoma de Madrid
}

\section{INTRODUCCIÓN}

Es un hecho reconocido, por obvio, que los estudios de toponimia se enfrentan necesariamente a problemas de gran calado, que han motivado en muchas ocasiones el escepticismo y la duda en no pocos filólogos y lingüistas. Ciertamente estos problemas existen y el escepticismo y la duda a que aludíamos están plenamente justificados en no pocas ocasiones. Efectivamente, el toponimista se encuentra a menudo en una suerte de elección imposible. Un estudio detallado de una zona muy limitada permite conocer en detalle la documentación a nuestra disposición de dicha zona, herramienta imprescindible del estudio, y permite conocer en lo posible los detalles de la evolución linguística del idioma preponderante en dicha zona, datos minuciosos del ámbito geográfico, etc. Todo ello hace que el estudio desarrollado de esta manera sea lo profundo y detallado que todos deseamos. Estos condicionantes, sin embargo, no parece que puedan darse en la misma medida cuando se estudia zonas muy amplias. No obstante, esta elección de una zona limitada plantea sus problemas, no menores que los que ofrece la elección de una zona muy amplia, pues el toponimista que estudia una zona limitada parece que dedujera que ésta es radicalmente distinta de las vecinas o no vecinas, lo que, evidentemente, nunca es verdad. Así, en no pocas ocasiones el toponimista por así decir "especialista" se enfrenta a problemas que no pueden ser solucionados con el material de su zona, ignorando el hecho cierto de que los datos de otras zonas pueden permitirle ver un problema determinado de una manera distinta. Nos hallamos, pues, ante una elección dificil, por no decir imposible. Se trata de elegir entre dos opciones imperfectas.

RFE, LXXXII, 2002, 3. ${ }^{\circ}-4 .^{\circ}$, págs. 295-317 


\section{UNA SERIE TOPONÍMICA INADVERTIDA HASTA LA FECHA}

En este orden de cosas hemos pretendido en el siguiente trabajo ejemplificar un caso en el que estudio de zonas amplias del territorio español permite ver los problemas en toda su complejidad. Hemos elegido una serie de topónimos que se extiende en una zona muy amplia, desde Badajoz a León, desde Jaén o Málaga a Palencia, Cantabria o Huesca. Muchos de estos topónimos reaparecen como antropónimos en cualquier lugar de España, sobrepasando claramente los ámbitos geográficos originarios. Hasta donde sabemos, la existencia de toda esta serie de topónimos y antropónimos no ha sido advertida hasta la fecha a pesar de que constituyen un complejo bastante abundante. Digamos, simplificando, que queremos llamar la atención sobre la existencia de decenas de ejemplos de topónimos acabados en - era, de significado desconocido, pero de origen latinorománico indudable ', aparentemente sacados a partir de una base que podría ser representada como marota/o, malotalo, *manotalo, marrota/o. Dicha base o nombre del cual parecen haber sido formados los derivados en era aparece representada también con relativa frecuencia. He aquí los ejemplos que de los aparentes derivados y de la base hemos coleccionado hasta la fecha ${ }^{2}$ :

\footnotetext{
${ }^{1}$ Creemos que la aparición del sufijo - ero/a muestra de forma inequívoca que el topónimo es latino-románico, y ello independientemente de cuál sea el origen del sustantivo o base del cual haya sido formado. Es evidente que la adición, productiva, det safijo a una base evidencia que ésta es analizada como palabra del idioma, lo que impide cualquier posibilidad de que se trate de un término prerromano. Es esto, probablemente, una obviedad, pero a menudo es ignorado. Sobre este sufijo puede verse ahora un resumen muy interesante, $\mathbf{R}$. Santiago Lacuesta y E. Bustos Gisbert, «La derivación nominal», Gramática descriptiva de la lengua española, dirigida por I. Bosque y V. Demonte, 3 vol., Madrid, Espasa Calpe, 1999, vol. 3, págs. 4506-4594, principalmente 4555-4560.

${ }^{2}$ La serie de ejemplos no pretende ser completa en modo alguno. De hecho, dado el estado de los estudios toponímicos en España a fecha de hoy, no puede serlo. Para esta relación hemos incluido tan sólo las provincias de España que cuentan con una relación toponímica más o menos completa. Ésta es fruto en muchas ocasiones de tos trabajos dirigidos en su momento por el profesor A. Ubieto Arteta (Repertorios de nombres geográficos), que abarcan las provincias de Ávila, Córdoba, Guadalajara, Segovia, Guipúzcoa, Huesca, Jaén, Murcia Teruel, Zaragoza. A estos trabajos hay que añadir lasdos magníficas monografias sobre las provincias de La Rioja y de Murcia de A. González Blanco, Diccionario de toponimia actual de La Rioja. Murcia, Universidad de Murcia e Instituto de Estudios Riojanos, 1987, Repertorio alfabético de la toponimia de la región de Murcia, Murcia, Editorial KR, 1998, así como la relación toponímica de la provincia de Palencia de F. R. Gordaliza Aparício \& J. M." Canal Sánchez Pagín, Toponimia palentina. Nuestros pueblos. Sus nombres y stus orígenes, Palencia, Caja España, 1993. Son también muy útiles, para el Principado de Asturias, Nomes de conceyos, parroquies, pueblos y llugares del Principáu d'Asturies, Academia de la Llingua Asturiana, Uviéu, 2000 y la serie de cuadernos por concejos que edita esta institución, que se acercan ya al centenar. Un inventario de todas las provincias andaluzas también está disponible en los correspondientes ocho volúmenes de Inventario de toponimia andaluza, editado por la Consejeria de Obtas Públicas y Transportes de esa comunidad autónoma. Por otra parte, dispongo, gracias a alumnos de la Universidad Autónoma de Madrid (Asignatura Introducción a la toponimia española), de un "vaciado" de las provincias de Ciudad Real y de Soria.
} 
Base 1. , Maroto,-a. Ámbito geográfico: Palencia, Segovia, Valladolid, Cuenca, Ciudad Real, Jaén, Málaga, Cáceres, Badajoz.

Maroto: Fuente de Maroto (E1 Real de San Vicente, Toledo), Palomar de Maroto (Madridejos, Toledo), Silo de Maroto (Tembleque, Toledo), Cañada de la Maroto (Huerta de Valdecarábanos, Toledo), Arroyo Maroto (Guadalcázar, Córdoba), Maroto ( Magaz, Villamediana, ambos Palencia), Camino Maroto (Osornillo, Palencia), Casa de Maroto (Marmolejo, Jaén), Casa el Maroto (Serrejón, Cáceres), Los Marotos (Torreperogil, Jaén), Casa de Maroto (Alburquerque, Badajoz), Vértice Maroto (Ontiñena, Huesca), Maroto (x2:Málaga, Rincón de la Victoria).

Marota: Arroyo de la Marota (Córdoba, Guadalcázar, La Rambla, La Victoria, todos municipios de Córdoba), Marotilla (Carbonero el Mayor, Segovia), Marota (Baeza, Jaén), Marotas (Arjona, Jaén), La Marota (Olmedilla de Éliz, Cuenca), Loma de la Marota (Villar y Velasco, Cuenca), La Marota (Sta. María la Real de Nieva, Segovia), Peña Marota (Polán, Toledo), La Marota (San Llorente, Valladolid); quizá también Marrota (Alcalá la Real, Jaén).

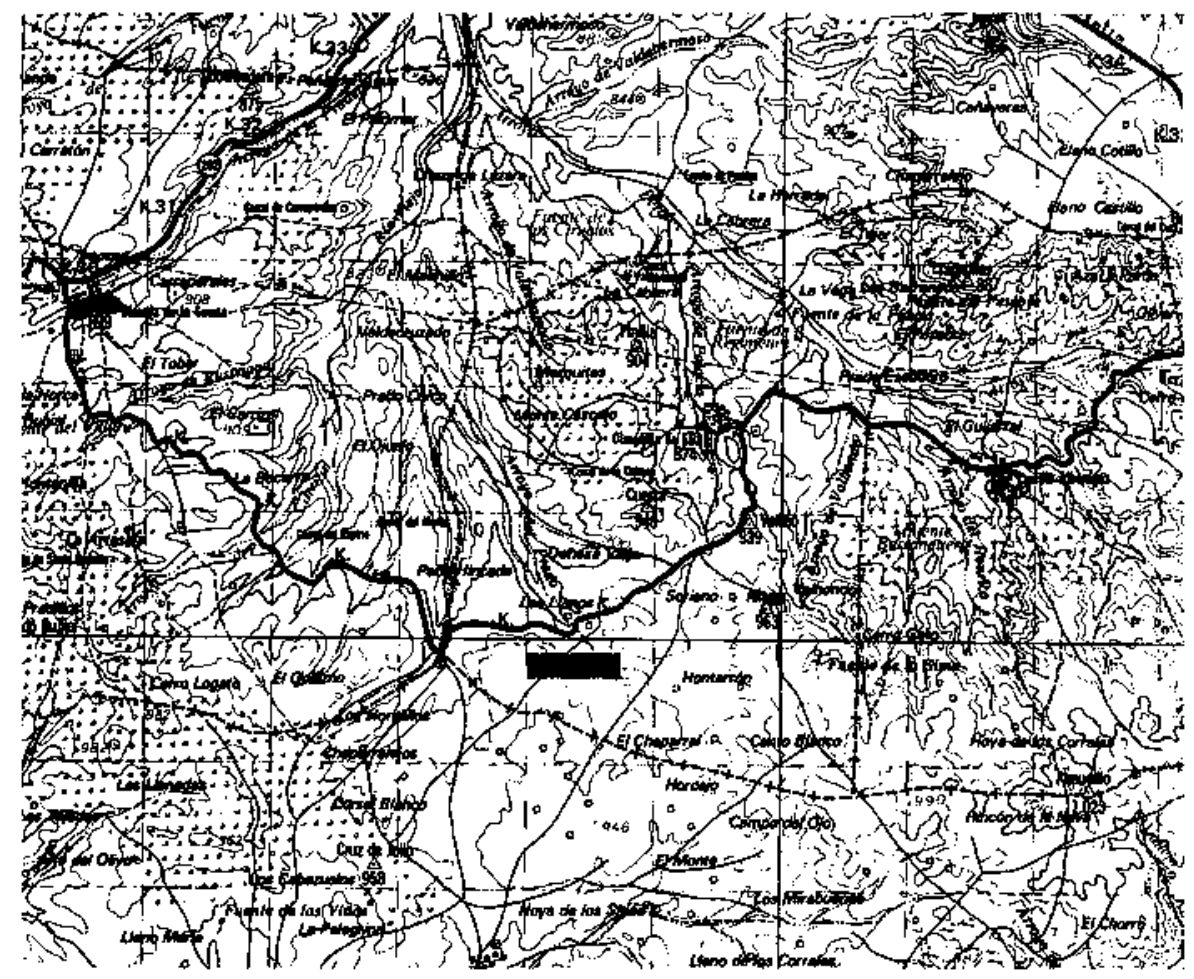

La Marota. Mapa 586 (Escala 1:50.000). Olmedilla de Éliz (Cuenca) 


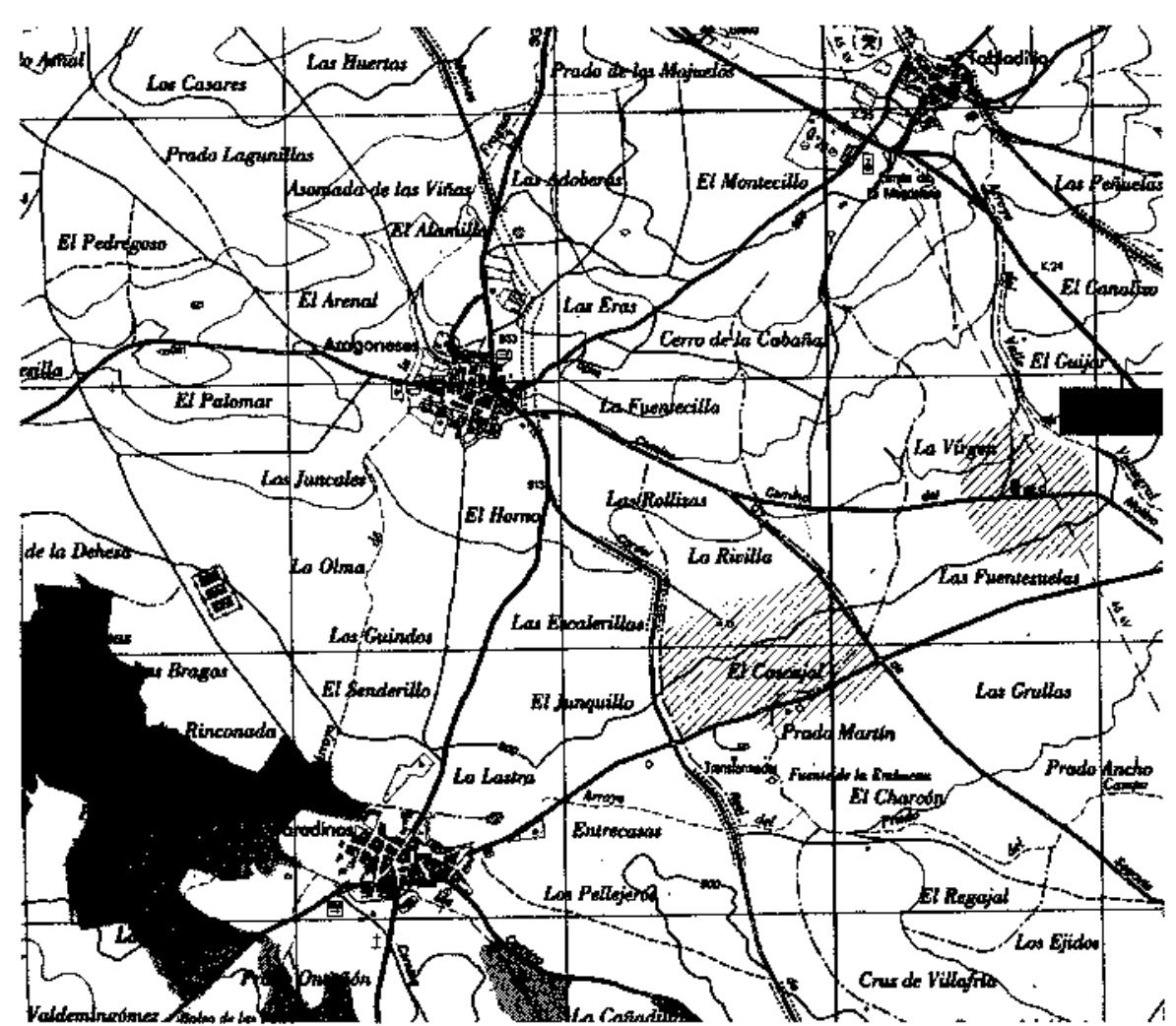

La Marota. Mapa 456-III (Escaja 1:25.000). Santa Maria la Real de Nieva (Segovia)

Marotón: Arroyo Marotón (Bodonal de la Sierra, Badajoz). Parece innegable que se trata de una derivado en -ón de cualquiera de los dos anteriores. No resulta fácil precisar si el significado es aumentativo o diminutivo.

Base 2.", Malota: Camino de Malota (Valseca, Segovia)

Formaciones de aparentes derivados en -ero/a:

1. A partir de Maroto, $\rightarrow$ a. Ámbito geográfico: Toledo, Madrid, Segovia, Badajoz, Cáceres, quizá Ávila.

Marotera: Senda de Maroteras (Carmena, Villamuelas, ambos Toledo), Marotera (Andújar, Jaén), Marotera (Castilblanco, Badajoz), Marotera (Pinilla del Valle, Madrid), La Marotera (Casas del Monte, Cáceres), Canal Marotera (Aznalcóllar, Sevilla), quizá también Despoblado Marateras (Gutierre Muñoz, Ávila); a lo que parece existe una variante con vibrante 


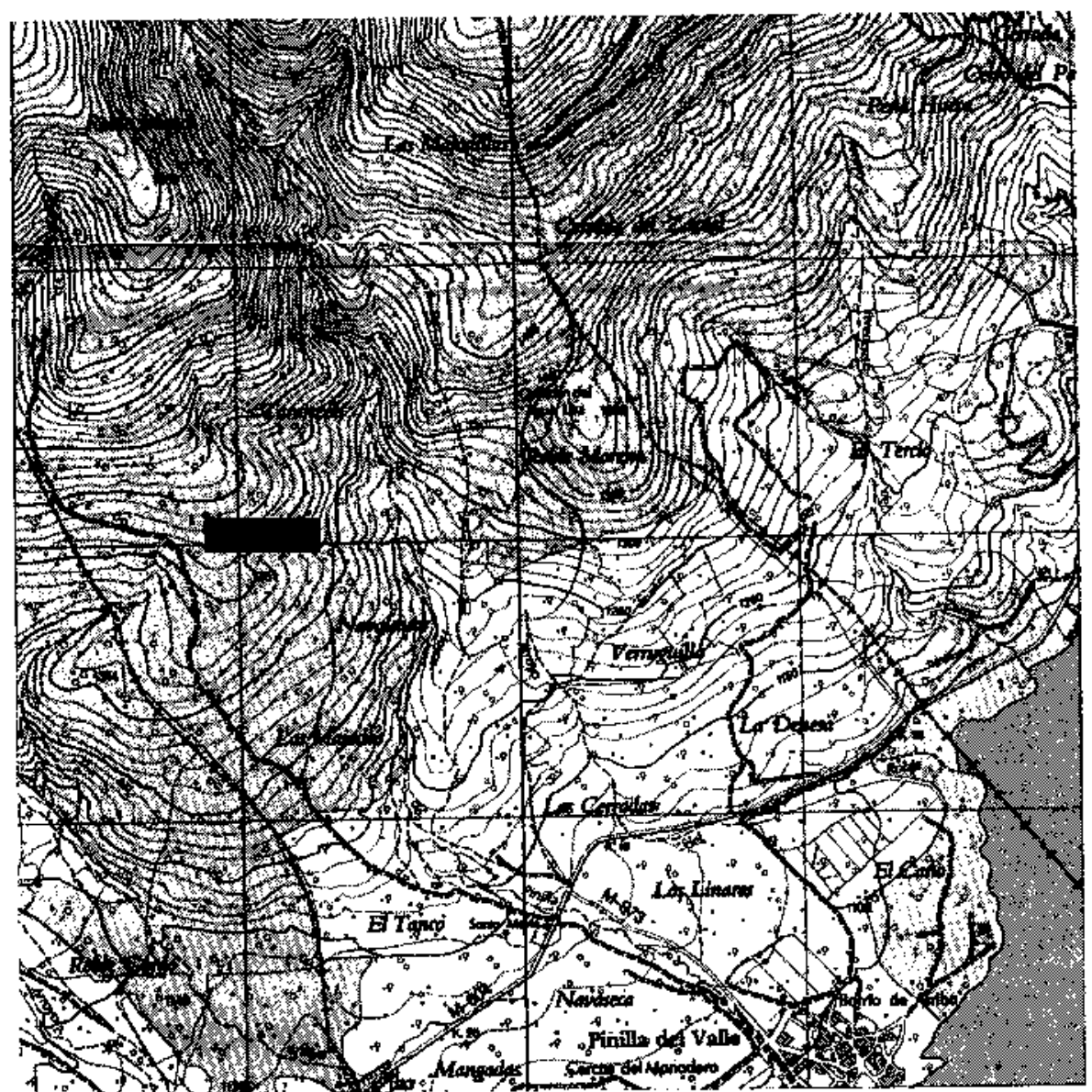

La Marotera. Mapa 484-I (Escala 1:25.000). Pinilla de Valle (Madrid)

múltiple, Las Marroteras (Revenga, Segovia), La Marrutera (Jerez de los Caballeros, Badajoz).

Marotero: Arroyo Marmarotero (San Martín de Montalbán, Toledo).

2. A partir de *Manoto, $-a$. Ámbito geográfico: Madrid, Toledo, Ávila, Segovia, Jaén, Ciudad Real, Badajoz.

Manotera: Arroyo de la Manotera (Calera y Chozas, Toledo), Las Manoteras (Segurilla, Toledo), Arroyo de las Manoteras (Parrillas, Segurilla, ambos Toledo), Camino de Manoteras (Órbita, Ávila), Las Manoteras (Yanguas de Eresma, Segovia), Manoteras (Higuera de Calatrava, Jaén), 
La Manotera (Casillas, Ávila), Camino de las Manoteras (Carrión de Calatrava-Torralba de Calatrava, Ciudad Real), Manoteras (Piedrabuena, Corral de Calatrava, Ciudad Real), Manoteras (Madrid) ${ }^{3}$, Las Manoteras (Puerto de Santa María, Cádiz).

Manotero: Manotero (Castuera, Badajoz), Camino del Manotero (Cabeza del Buey, Badajoz), formación diminutiva Manoterillo (Cabeza del Buey, Badajoz).

3. A partir de Maloto, $\rightarrow a$. Ámbito geográfico: Ávila, Toledo, Ciudad Real, Badajoz.

Malotera: Las Maloteras (Guadamur, Toledo), Las Maloteras (Valenzuela de Calatrava, Ciudad Real), Maluteras (Santa María del Berrocal, Ávila), Las Maluteras (Puebla del Prior, Badajoz).

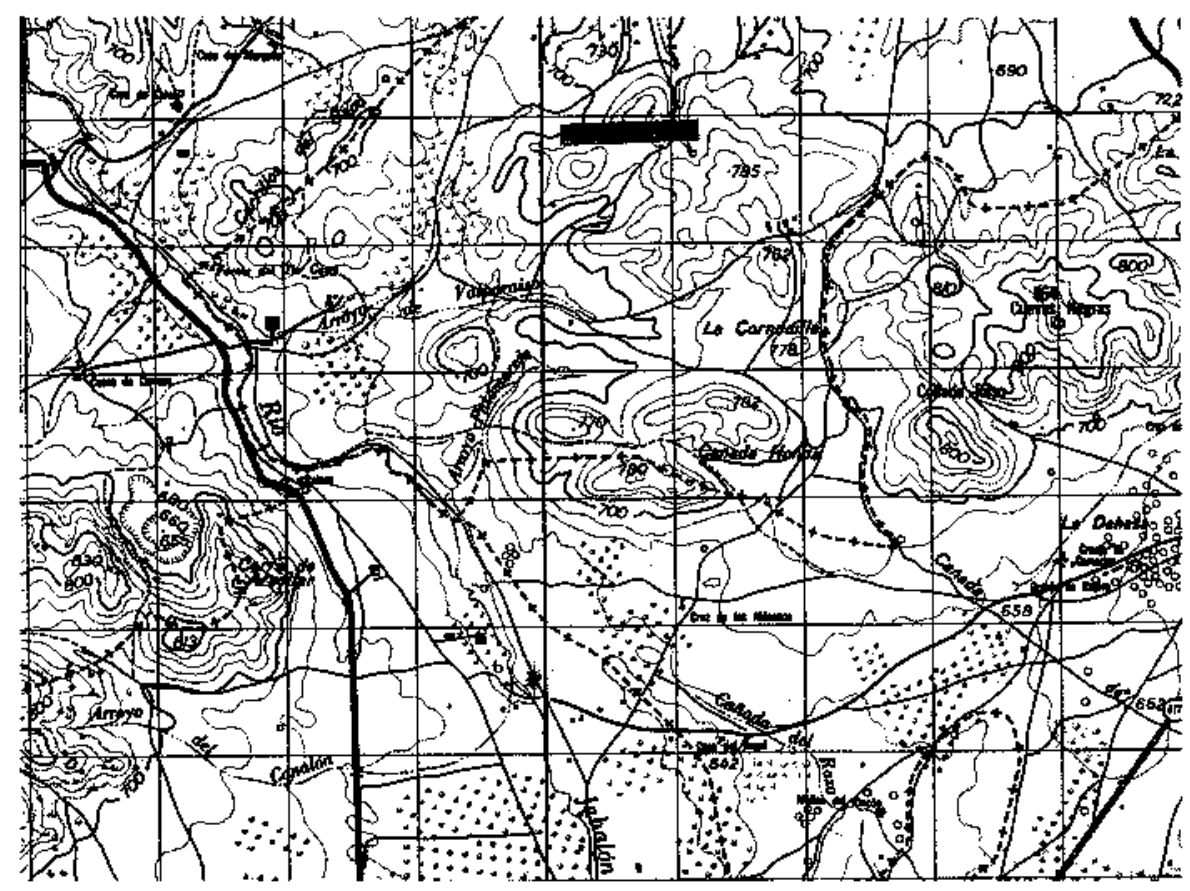

Las Maloteras. Mapa 81 I (Escala $1: 50,000$ ). Valenzuela de Calatrava (Ciudad Real)

\footnotetext{
3 Todavía figura Camino de las Manoteras en el Mapa Topográfico Provincial del año 1875 , reeditado en 1982.
} 


\section{HiPÓTESIS PREVIAS}

Hasta donde sabemos, como señalábamos con anterioridad, el hecho aparente de que los topónimos en -ero/a están relacionados con las bases apuntadas no ha sido señalado hasta la fecha, y ello nos parece que es un hecho esencial que ha de ser considerado en buena medida punto de partida de cualquier intento de vislumbrar una solución. Conocemos una hipótesis ${ }^{4}$ en torno a Manotero, Manoterillo y dos en tomo a Maroto/a, sin que ni una ni otras relacionen ambas series toponímicas ni conozcan la amplia extensión de la serie toponímica que hemos relacionado más arriba.

2.1. En efecto, se ha propuesto para los topónimos pacenses Manotero y Manoterillo una relación con La Manea (Castuera, Badajoz) y Manilla de Sancho Blasco (Zalamea de la Serena, Badajoz), entendiendo que todos ellos son derivados en última instancia de mano. Se propone que en La Manea hallamos la voz manea, que es la cuerda con la que se tira de las bestias, noción esta que se expresaría también con la voz maniota, de la que derivarian nuestros topónimos ${ }^{5}$. La hipótesis, en principio quizá verosímil para $L a M a-$ nea ${ }^{6}$, se enfrenta a inconvenientes que nos atrevemos a juzgar de importancia. Podríamos citar, entre otros, el hecho cierto de que, a lo que sabemos, e] derivado *manotero, — $a$ no está documentado en parte alguna, como tampoco la forma en principio esperable *maniotero, - $a$. Al margen de ello, a nadie puede escapar que la aceptación de esta hipótesis conllevaría necesariamente dificultades de peso para incluir Manotero, $-a$ en el conjunto toponímico que hemos señalado más arriba. Así, valga por caso, las formas del tipo Marotero, - $-a$ y Malotera, $\longrightarrow-0$ sólo podrían ser explicadas como variantes fonéticas de la anterior. Ello en principio no parece absolutamente imposible, pero entonces quedarian sin explicación formas del tipo Maroto, $\longrightarrow a$, en donde la evolución fonética parece imposible.

A propósito de Manotero, $-a$ debemos incluir aquí la existencia aparente del vocablo como nombre común en una limitada zona de Aragón. En efecto, es de notable interés la inclusión por R. Andolz, en su conocido diccionario?,

${ }^{4}$ A. M. ${ }^{3}$ Castaño Fernández, Los nombres de La Serena, Mérida, Editora Regional de Extremadura, 1998, pág. 277.

${ }^{5}$ DRAE, manea: "Cuerda para atar las manos de un animal, maniota, apea». maniota: "Cuerda con que se atan las manos de una bestia para que no se huya".

${ }^{6}$ Es evidente que la aplicación toponímica del vocabjo, sin ser imposible, requiriría mayor explicación. Partiendo de mano cabrian otras posibilidades. Asi, valga sólo a titulo de ejemplo, J. M. Sánchez Miguei, Diccionario del habla toledana, Toledo, Diputación Provincial, 1998, pág. 201 recoge maneo como "turno de riego", lo que parece de más fácil aplicación toponímica.

7 R. Andolz, Diccionario aragonés, Zaragoza, Mira Editores, 4." edición, 1992, pág. 280. 
de la voz como exclusiva de Borrés (Zaragoza) con el significado de 'madreselva'. Desconocemos cualquier otro testimonio de este vocablo, pero creemos que debe ser separado del conjunto de topónimos que estudiamos por varias razones. En primer lugar porque se trata de una palabra de origen y existencia oscuras ${ }^{8}$ limitada a una zona muy pequeña, que precisamente desconoce el uso de Manotera como topónimo; en una segunda instancia, porque la proposición de este origen, como sucedía en el caso de la hipótesis anterior, implicaría forzosamente la separación de Marotera, Maroto, etc.

2.2. Las dos opiniones que conocemos en torno a Maroto/a coinciden en atribuir un origen antroponímico a estos topónimos. J. Coromines, en efecto, al parecer sin conocimiento de las formaciones en - era/o ni de las variantes formales señaladas, ha aventurado una explicación para Maroto, que él entendió como antróponimo valenciano ${ }^{9}$. Coromines piensa que Maroto es una forma disimilada de Moroto. Uno y otro tendrían su origen en el árabe vulgar murâbt, 'guerrero, conquistador por la fe musulmana' ${ }^{10}$. La /a/ entre las enfáticas $/ \mathrm{r} / \mathrm{y} / \mathrm{t}$, sonaría muy velar por lo que habría sido adoptada por catalanoparlantes o por mozárabes como $/ \mathrm{o}$, añadiendo también $/ \mathrm{o} /$ final. Cita el lingüista catalán a este propósito los topónimos Canal d'en Moroto, en la Albufera de Muro-Alcudia, Torrent de Can Moroto, también en Alcudia. No cita ningún ejemplo toponímico de Maroto, pero sí hace alusión a que éste es un apellido bastante extendido en la isla de Mallorca. Termina su breve nota señalando que «l'etimologia murabt s'imposa».

Por otra parte, B. Sanz Alonso, en un estudio de toponimia vallisoletana ${ }^{11}$, recoge $L a$ Marota en dicha provincia e incluye, sin más detalles, este topó-

\footnotetext{
${ }^{8}$ Quizá el origen del significado 'madreselva' sea, en última instancia, el mismo que el del significado 'cuerda para atar las manos de un animal'. La madreselva, de alguna manera, "abraza" o "ata" en su crecimiento. El mismo vocablo madreselva puede indicar, a nuestro juicio, esta imagen, recurriendo, en una metáfora muy expresiva, a señalar esta planta como 'una madre que abraza'. Esta imagen está presente con toda claridad en otras designaciones de esta planta, del tipo cat. lligam de bosc. Puede compararse también el común liana, del fr. liane, o, mejor aún, enredadera. La misma imagen también aparece en lat. hedera, 'hiedra', de una conocida raiz indoeuropea del significado 'coger, agarrar', cf. praehendo, 'coger', praeda, 'botin', etc.

${ }^{9}$ J. Coromines, Onomasticon Cataloniae.Els noms de lloc i noms de persona de totes les terres de llengua catalana, Barcelona, Curial, vol. 5, pág. 393. Ni Moroto ni Maroto fíguran en la obra de F. de B. Moll, Els llinatges catalans (Catahnya, País Valencià, Illes Balears), Moll, Palma de Mallorca, 1982.

10 Naturalmente, es éste el vocablo árabe que ha dado lugar a port. almorávida, esp. amorávid(e), cat. almoràvit. Con una importante diferencia de significado es también el origen del esp. maravedi, morabati, etc. Para detalles sobre esta cuestión, F. Corriente, Diccionario de arabismos y voces afines en iberorromance, Madriơ, Gredos, 1999, pág. 201.

"B. Sanz Alonso, Toponimia de la provincia de Valladolid. Las cuencas del Duero, Pisuerga y Esgueva, Valladolid, Universidad de Valladolid, 1997, pág. 400.
} 
nimo en un capítulo de antropónimos y poseedores. Parece evidente, aunque no se expresa textualmente, que se entiende que La Marota es una especie de derivado del nombre femenino María.

Aun a pesar de la genialidad del insigne lingüista catalán somos nosotros de la opinión de que la hipótesis murabt, lejos de imponerse, es imposible. Esta imposibilidad se desprende de alguna manera del conocimiento parcial de los datos, pues la hipótesis no tiene en cuenta ni la extensión de Maroto, ni sus variantes, ni las formaciones en - era/o de aparentes derivados. La evolución fonética que Coromines nos propone es probablemente muy poco verosímil ${ }^{12}$, pero el problema que genera su imposibilidad es ante todo su incapacidad absoluta para dar cuenta de Marotera, Manotera, etc. En buena medida, también estas dificultades obstaculizan la hipótesis de Sanz Alonso, presente en un trabajo por lo demás de calidad y muy documentado. No se tiene en cuenta la aparición del topónimo con otras variantes formales en otras regiones, del tipo Manauta, Manotá ni se puede explicar con la hipótesis María los derivados del tipo Marotero, Marotera, etc.

\section{NUESTRA HIPÓTESIS}

En efecto, a nuestro parecer tanto Maroto como Marotera, Manotera, etc. no son en absoluto antropónimos mallorquines o valencianos de origen árabe, ni tampoco tienen relación con el antropónimo María como tampoco creemos que sea verosímil partir de manea o mano para explicarlos. Creemos que puede ser razonable una hipótesis que, en lo sustancial, proponga un mismo origen para todo el conjunto toponímico, lo que en principio acarrea importantes ventajas. Está claro que en muchos casos se trata de antropónimos, pero en un uso secundario a partir de un origen toponímico. Se trata, en efecto, a nuestro parecer más bien de topónimos primarios. Como sucede tan a menudo en el ámbito toponímico su explicación reposa pura y sencillamente en el cotejo de series muy amplias de topónimos procedentes de zonas muy extensas. Sólo este cotejo permite vislumbrar en ocasiones las evoluciones fonéticas extremadas que han tenido lugar. Creemos en efecto que la explicación más sencilla y verosímil de esta serie toponímica, que por lo demás podremos ver más adelante que es de una extensión aún mayor, puede sustentarse en la suposición de topónimos compuestos de diversos nombres derivados de lomalo y un adjetivo oto o su derivado otero/a, esto es, 'loma alta', noción muy sencilla y natural.

\footnotetext{
${ }^{12}$ Así, por ejemplo, la síncopa de /i/ no sabemos si cuenta o no con otros paralelos. Sabemos, por el contrario, que la adaptación normal del término en las lenguas españolas cuenta siempre con dicha $f$ it.
} 
3.1. En el caso de Maroto/a creemos que hay que partir de una formación lomaroto, en donde lomar es evidentemente una derivado secundario del común loma, lomo (<lat. lumbu) ${ }^{13}$ y oto el resultado regular en amplias zonas de España del latín altu. El término lomar existió con seguridad absoluta, como muestran muchos topónimos del tipo Lombarejos (Villaviudas, Palencia), Camino de Lomar (Fanlo, Huesca), Lomarón (Aísa, Huesca), Lombarin (Autol, La Rioja), Lombaraón (Villoslada, La Rioja), Lomaritas (Linares de Mora, Teruel), etc. A nuestro juicio tienen un gran valor aqui casos como Fuente de Umarinos (Aguilar de Campoo, Palencia), en donde junto a un diminutivo de nuestra voz lomar hallamos un cierre de $/ 0 /$ en $/ u /$ en sílaba inicial, muy frecuente, y, sobre todo, la deglutinación de $/ /$, entendida como artículo. Nos parece que el proceso ha sido bastante complicado. Se ha producido, probablemente en los compuestos y derivados, primero una asimilación de $/ \mathrm{o} / \mathrm{a} / \mathrm{a} /{ }^{14}$ de la sílaba siguiente: el lomar oto $>$ el lamaroto, con posterior y natural deglutinación de un falso artículo la maroto o bien deglutinación de /l/ y posterior aféresis de /a/, esto es, el lomar oto $>$ * el lamar oto $>$ la maroto $>$ la marota o bien *el lamar oto $>$ el amaroto $>$ el maroto. En el primero de los casos la aparición de un artículo femenino ha generado en ocasiones el cambio de la vocal final del compuesto, para dar una apariencia femenina, produciéndose así marota ${ }^{15}$. Todo esto es algo, desde luego, muy

\footnotetext{
${ }^{13}$ La utilización orográfica del vocablo, a lo que parece, tan antigua como extendida en territorio español, probablemente de época latina tardia, es común y frecuentisima en castellano y gallego-portugués. Vid. W. Meyer Lübke, Romanisches Etymologisches Wörterbuch (REW), Heidelberg, Carl Winter, 1930, 5160 lumbus. No aparece como tal en el dominio catalán norteño, pero sí en la toponimia y el uso vivo valenciano y en la toponimia mallorqujna desde muy temprano, lo que parece excluir el castellanismo. Es digno de mención aqui el hecho de que el vasco bizkar significa tanto 'lomo' de un animal o persona, como 'loma'. Esto puede mostrar tanto influencia romance como evolución paralela, pero no dispongo de datos para inclinarme a favor de uno u otro hecho. Se señala la existencia en latín de una formación dirninutiva en concurrencia lumbulu. 'Iomillo', presente en oc. ant. lomble, cat. llomble, etc. Destacamos aquí su aparición, a lo que sabemos no constatada hasta la fecha, en Lomblovedao (Mansilla, La Rioja). El topónimo aparece en la excelente monografía de F. González Bachiller, Aspectos fonéticos de la toponimia riojana actual, Logrono, Universidad de La Rioja, 1997, pág. 77. La imagen toponímica entra dentro de una amplia serie de partes del cuerpo humano o animal para la expresión de accidentes orográficos, del tipo cabezo, a, cuello, cuesta, pico, morro, rosiro, etc.

${ }_{14} \mathrm{La}$ viabilidad fonética de esta asimilación no creemos que plantee escrúpulo alguno. En todo caso, puede cotejarse ejemplos poco menos que seguros: Cerro de la Lambarrasa (San Pedro del Romeral , Cantabria), con $849 \mathrm{~m}$. de altitud.

is Damos por hecho que el género del derivado en -ar sería masculino, aun cuando hay motivo para pensar que la posibilidad femenina también existía. En esa dirección parecen apuntar ejemplos como Alomar (Vertavillo, Palencia), que muestra, a nuestro parecer, aglutinación de /a/ del articulo, ${ }^{*}$ La Lomar $>$ Alomar. Muy semejante es La Aloma (Cervera de Pisuerga, Palencia).
} 
frecuente, tanto en el dominio general de cualquier idioma con artículo, como sobre todo en el terreno toponímico ${ }^{16}$. Pueden citarse fácilmente otros muchos casos de deglutinación de $/ 1 /$ en derivados toponímicos de lat. lumbu: El Lombo Ombellano ${ }^{17}$ (Viniegra de Abajo, La Rioja), "loma llana', El Ombillo (Hornillos, La Rioja), La Umbilla (Canales, La Rioja), El Hombo (Santa Engracia, La Rioja), Ombillos (Moratalla, Murcia), El Homillo (San Andrés, La Rioja), Omillas (Albelda, Huesca), Barranco de Ombo (Novallas, Zaragoza), El Homillo (Torrelapaja, Zaragoza), Cañada del Humiello (Cuevas de Provanco, Segovia). De la misma manera podemos citar casos semejantes con eliminación de toda la sílaba inicial, sean cuales sean los detalles del proceso: así de un derivado en -on, ona del anterior, lomarón, lomarona, Marona (Anzánigo, Huesca), Marones (Ejea de los Caballeros, Zaragoza), Cerro Marmayor (Clavijo, La Rioja), igual en casi todo a Cerro Otero Mayor (Merindad de Valdeporres, Burgos), Mumayor (Cudillero, Asturias) <lat: monte maiore, Marmalejo (Santa Eulalia Bajera, Préjano, ambos en la Rioja) ${ }^{18}$, como Mumalo ( Grau, Asturias) <lat. monte malu; La Marona (Revenga de Campos, Palencia) ${ }^{19}$, Marón (Venta de Baños, Palencia), Los Marones (Calzada de los Molinos, Palencia), con dudas Maranchón (Guadalajara), Marcalva (Villarabé,

${ }^{16}$ Omitiremos casos como esp. atril < lat. lectorile, ovillo $<$ ant. lovillo $<$ lat. globellu para citar algunos ejemplos de topónimos en gerieral poco conocidos: La Una (Cobos de Cerrato, Palencia), La Unilla (Briñas, La Rioja), claramente laguna. Evidentemente, el fenómeno contrario, esto es, la aglutinación del artículo a la palabra es también muy frecuente, tanto en nombres comunes como en topónimos. Considérese, valga por caso, ejemplos del tipo fr. lierre < lat. hedera, 'biedra', cat, arrel <lat, radice, etc. Es muy ilustrativa a este propósito la convivencia en catalán de dos términos para la expresión de 'ombligo' del mismo étimo, en uno de los cuales se ha producido esta agfutinación, mientras que en ef otro se ha producido aféresis: llombrigol, melic < umbiliculu, umbilicu. Nótese que en llombrigol la aglutinación del articulo ha precedido a la palatalización catalana de $/ /$ en posición inicial de palabra, to que evidencia su gran antigüedad. En el campo de la toponimia es un hecho frecuentísimo. Por citar ejemplos de ruestro mismo campo léxico: $\mathrm{Ce}$ rro Lutero (Nalda, La Rioja), Pico Lutero (Tabanera de Valdavia, Palencia), Los Loteros (La Lagunilla, La Rioja), etc.

${ }^{17}$ Es éste a mi parecer un ejemplo espectacular de tautologia toponímica, tan frecuente. Junto a ombe < lombo se repite otra vez lombo. Existe quizá otro ejemplo igualmente brillante y aún más dificil en el caso del topónimo toledano Marmarotero, en donde a Marotero, procedente de lomar otero, con deglutinación de la silaba inicial, se ha antepuesto otra vez lomar, igual que en El Lombo Ombellano. En este caso, como decimos, se ha ido aún más lejos, pures la segunda forma antepuesta ha vuelto a sufrir la deglutinación: (Lo)mar(Lo)marotero.

${ }^{18}$ Este topónimo debe ser analizado rectamente como 'lomarejo malo', con la precisión de que el sufijo de diminutivo - ejo se añade al compuesto lomarmalo y no al adjetivo. Es algo muy frecuente en compuestos toponímicos por así decir "soldados estrechamente", del tipo Honsequilla (Corraies de Duero, Valladolid),

${ }^{19}$ Nótese que ejemplos como éste son muy ilustrativos. Hablamos de deglutinación de falso artículo un tanto impropiamente, atendiendo tan sólo a bechos gráficos, pues es evidente que la pronunciación es /lamaróna/. 
Palencia), etc; de manera parecida, Omadillas (Boada de Campos, Palencia) muestra claramente deglutinación de /1/, presente aún en La Lomadilla (Cervera de Pisuerga, Palencia). Los ejemplos son más abundantes de lo que se puede citar aquí.

En lo sustancial la explicación es la misma para Marotera, Marotero. La única diferencia formal estriba en que, más que propiamente hablando de derivados, se trata de formaciones paralelas en las que a lomar se ha añadido otero, voz bien conocida, cambiada secundariamente en otera por las razones de concordancia de género aludidas más arriba: lomar oto /// lomar otero >> la maroto > la marota // la marotero > la marotera. La unión de estos términos, prácticamente sinónimos en origen, encuentra numerosos correlatos en topónimos del tipo Monte Otero (Aguilar de Campoo, Palencia) ${ }^{20}$, Otero Lomizo, Otero Monte, Pico de Lomalta (Villar del Cobo, Teruel), mejor aún quizá Lombatero (Areños, Palencia), si es que procede de ${ }^{*}$ lomba otero y no se trata, como también es posible, de un derivado en -ero de lombato o lombata ${ }^{21}$.

3.2. Hay razones para creer que junto al derivado de loma en -ar existió también un derivado en -analo con la forma lomana, lomano, lombana, lombano ${ }^{22}$. No es un vocablo solamente teórico, pues la toponimia de algunas zonas de España, particularmente Palencia, Burgos, León, Zamora, también Galicia, lo conserva intacto en algunas ocasiones: Llombana (Perarrúa, Huesca) ${ }^{23}$, Las Lomanas (Cervera de Pisuerga, Sotobañado y Priorato, ambos en Palencia), Los Lomanos (Cervera de Pisuerga, Mazariegos, ambos en Palencia), Lomanillo (Medianas, Burgos), El Lomano (Santibáñez de la Peña, Palencia), La Lomanilla (Guardo, Saldaña, Santibáñez de la Peña, Bahíllo, todos en Palencia), Los Lomanillos (Cervera de Pisuerga, Areños, los dos en Palencia), Lomaniel (Castrejón de la Peña, Palencia), La Lombanilla

\footnotetext{
${ }^{20}$ Junto a Montotero existe muy frecuentemente Montoto (asi Berzosilla, Palencia), Montouto (por ejemplo, A Veiga, Asturias). Repárese en que la pareja Montoto-Montotero es igual que nuestra hipotética Maroto-Marotero.

${ }^{21}$ Este derivado en - ato de lomba, loma encuentra paralelos evidentes en el mismo ámbito léxico en casos como poyato, cerrato, molata, serrata, etc. Así, valga por caso, Las Poyatas (Espeja de San Marcelino, Soria), Loma de la Molatica (Férez, Albacete), Cerratón de Juarros (Burgos), Sierra de la Cerrata (Almadenejos, Ciudad Real), Cerro Mulatón (Aldea del Rey, Ciudad Real), El Serrato (Campoo de Yuso, Cantabria), etc.

${ }^{22}$ Para la formación, compárese solana, quintana, Campanos (Santa Marina del Rey, León) <campo, la Pozana (Aguilar de Campoo, Palencia) <pozo, poza, La Poyana (Frómista, Palencia) <poyo, La Costana (Campoo de Yuso, Cantabria), etc. Para la convivencia de tres sinónimos como cuesta. costana y costera en la ribera del Huecha, J. A. Frago García, Toponimia del Campo de Borja. Estudio lexicológico, Zaragoza, Diputación Provincial, 1980, págs. 88-90. Compárese con esta serie nuestros lomo/a, lomana, lomero/a

${ }^{23}$ Vid. a este propósito J. A. Frago García, op. cit. pág. 221, nota 283.
} 
(Sampil de Sanabria, Zamora), El Lombano (El Burgo Ranero, León), Lomana (Valle de Tobalina, Burgos) ${ }^{24}$, La Lombana (Riotuerto, Cantabria), Solambano (Santas Martas, León) ${ }^{25}$, Lombanico (Santas Martas, León), Llombano (Concejo de Quirós, Asturias), Los Lombanos (Carranza, Vizcaya), Lombao (Ortigueira, A Coruña), Lombao (Paradela, Lugo), etc. Debe incluirse aquí también Lomaniel (Castrejón de la Peña), con apócope de /o/ a partir de un diminutivo lomanillo y muy probablemente también Nomanillas (Castrejón de Ia Peña, Palencia), con asimilación de /1/ a las consonantes nasales siguientes o bien deglutinación del artículos y posterior aglutinación de /n/ de la preposición en, y con dudas Solamanilla (Pajares, La Rioja), con anteposición de la preposición so- a una forma lamanilla, a su vez de lomanilla y Tras de la Mano (Aguilar de Campoo, Palencia), muy posiblemente *Tras de lomano con la asimilación vocálica que hemos comentado con anterioridad. El vocablo aparece repetidas veces en documentación medieval latina, al menos en zona asturleonesa: $A C L$ 896, $931 \mathrm{de} \mathrm{ri-}$ bu quod dicunt Auoceto, discurrente aqua per lumbano de parte occidentis; $A C L 329_{18}, 960$ alia de illa lumbana; $A C L 341_{17}, 961$ uinea de lombana una.....in lombello de arrutura, etc. ${ }^{26}$. Es muy clarificadora aquí la presencia, como en todos los casos anteriores, de formas de este término con deglutinación de /// entendida como artículo. Los casos son, otra vez, muy abundantes en la provincia de Palencia: Humanillo (Piña de Campos, Palencia), El Humano (Fuentes de Valdepero, Mantinos, Mudá, Salinas de Pisuerga, todos en Palencia); la forma con apócope Lomaniel nos aparece también con deglutinación y aféresis en Maniel (Bahillo, Palencia). Como en el caso anterior parece, por tanto, que debemos suponer para la explicación de Manoto/a y Manotero/a compuestos como lomanalo otola y lomana/o otera/o con deglutinación de toda la sílaba inicial. Así pues, lomana ota $>$ l'omanota > la manota, lomana otera $>$ l'omanotera $>$ la manotera. La corrección de esta explicación es avalada, además de por todo el conjunto de topónimos que estamos comentando, por casos como el del topónimo Manauta $^{27}$, en donde la ausencia de monoptongación del diptongo secundario muestra bien en esta dirección. A lo que parece, junto a lomano

\footnotetext{
${ }^{24}$ Muy interesante aquí Madoz: «Situada en una loma que se estiende en dirección.......» El topónimo aparece documentado en 1074 con la forma Lombana. Vid. R. Meréndez Pidal, Origenes del español. Madrid, Espasa-Calpe,1986, 10. ${ }^{\circledR}$ edición, pág. 287.

${ }_{25}$ Debe entenderse 'bajo el lombano'. Nótese especialmente la asimilación de /o/ inicial a /a/ y la anteposición de la preposición so.

${ }_{26}^{26}$ Los datos proceden de M. ${ }^{2}$ Pilar Álvarez Maurín, Diplomática asturleonesa. Terminologia toponimica, León, Universidad de León, 1994, pág. 95.

${ }^{27}$ Lamentablemente no hemos conseguido localizar este topónimo, si es que aún exjste. Con todo, puede asegurarse con un margen de duda pequeño su realidad, toda vez que es apellido de claro origen toponímico.
} 
existió también una variante con apócope de /o/, presente al menos en la zona central de España. Creemos, en efecto, que es ésta la explicación más verosímil de casos como Humanes (Madrid), Humanes de Mohernando (Guadalajara) ${ }^{28}$, Molino Humanes (Castillo de Locubin, Jaén) ${ }^{29}$. Nótese en estos ejemplos la deglutinación de $/ / /$ y el cierre de $/ o /$ inicial en $/ \mathrm{u} /$ que hemos hallado con cierta frecuencia en casos como Umarinos, El Humano, etc. ${ }^{30}$. Con dudas puede señalarse otra vez una variante con deglutinación de la sílaba inicial en Fuente Man (Villovieco, Palencia), que sería así muy semejante a Fuente Loma (Capillas, Palencia).

3.3. Podemos creer, en fin, que existió también otro derivado en —al, de significado igual a los anteriores, lomal, si bien, a lo que parece, mucho menos frecuente ${ }^{31}$. La unión a este sustantivo lomal de una forma adjetival otero,a y procesos fonéticos semejantes o iguales a los comentados más arriba dieron lugar a La Malotera.

\section{TOPÓNIMOS EMPARENTADOS CON LA PREPOSICIÓN SO}

4.1. En estrecha relación con los topónimos que hemos estudiado como parte central de esta nota, creemos que no son en modo alguno pocos los ejemplos de topónimos emparentados, pero precedidos de la preposición $s o$, que con el significado de bajo, debajo de' debia ser utizada necesariamente para la indicación de lugares que se hallaban 'debajo de una loma, debajo de un lomar, debajo de una lomana'. Se trata, por tanto, de la misma imagen toponímica que hallamos repetidas veces en todos los territorios españoles. Esta imagen se expresa con la preposición so precediendo a términos del mismo campo semántico: cueto, piedra, peña, monte,

\footnotetext{
28 A lo que sabemos no se ha propuesto ninguna explicación para el topónimo madrileño. Para el alcarreño se puede consultar E. Monge Molinero, Topónimos de la provincia de Guadalajara, Sigūenza, Ed. autor, 1993, pág. 97 y J. A. Ranz Yubero, Toponimia mayor de Guadalajara, Guadajajara, Alfoz, 1996, pág. 154. Monge apunta una relación con lat. humus, mientras que Ranz señala varias hipótesis en nada verosimiles, salvo la ya citada de una relación con humus.

${ }^{29}$ No se puede excluir aquí que sea Humanes antropónimo.

${ }^{30}$ Es un hecho, por lo demás, frecuentísimo, un poco por todas partes. Compárese, circunscribiéndonos tan sólo a Palencia, Suiglesia (Castrejón de la Peña), Sucuesta (Fresno del Rio) con Solaiglesia (Cervera de Pisuerga), Solacuesta (Castrillo de Villavega).

${ }^{31}$ Se puede hablar de -al y —ar como variantes alomórficas de un mismo sufijo. En este orden de cosas la convivencia y homonimia de lomal y lomar no es sorprendente y cuenta con muchos paralelos, del tipo manzanal/manzanar, retamar/retamal, etc. Para detalles sobre estos sufijos, R. Santiago Lacuesta y E. Bustos Gisbert, «La derivactón nominal», I. Bosque y V. Demonte (eds.), op. cit., vol. 3, págs. 4527-4529.
} 
poyo, otero, etc. y el nuestro mismo, loma. Algunos ejemplos pueden ser ilustrativos ${ }^{32}$ :

4.1.1. Rom. cuello y derivados: Sulcullau Bringales (Miranda, Asturias), Socollao (La Pernía, Cantabria), Socuello (Bembibre, Alcoba de la Ribera, ambos en León), etc.

4.1.2. Rom. cueto: Alto de Zocueto (Valle de Mena, Burgos), El Sucue$t u$ (Tineu, Asturias)

4.1.3. Rom. lastra: Solalastra (Aguilar de Campoo, Cervera de Pisuerga, Olmos de Ojeda, los tres en Palencia).

4.1.4. Rom. losa: Solallosa (Oviedo, Asturias), Solallosica (Llaviana, Asturias).

4.1.5. Rom. mirón <mira, esto es, 'lugar alto de observación': Gallegos de Solmirón (Salamanca), Para la presencia de mirón, mira, compárese: $A l$ tamira (Cantabria, pero con centenares de ejemplos en toda la España de habla castellana), El Mirón (x9 sólo en la provincia de Palencia), La Mirilla (Payo de Ojeda, Palencia).

4.1.6. Lat. monte: Solmonte (Aguilar de Campoo, Palencia), Somonte (Palma del Río, Córdoba), Somonte (Gijón, Asturias), Salmonte (apellido), etc.

4.1.7. Rom. alto, outo y derivados: Solotero (Amayuelas de Arriba, Palencia), Solutero (Payo de Ojeda, Palencia), también aquí Sotal (Aguas, Liesa, etc., todos en Huesca), a partir de otal, como en el tautológico Alto Otal (Torla, Huesca), etc.

4.1.8. Lat. pinna: Sopeña (Foncea, La Rioja), Solapeña (Ampudia, Palencia), Solapenilla (Munilla, La Rioja), Sopeñillas (Dehesa de Montejo, Palencia), Sopeñota (Pomar de Valdivia, Palencia), La Sopeña (Valdegovia, Álava), Sopena (Graus, Huesca), Sopeñano (Valle de Mena, Burgos), Sulapena (Miranda, Asturias), Xupena (Orba, Alicante), Salape$\tilde{n} a$ (apellido), etc.

4.1.9. Lat. petra: Sopeira (Huesca), Fuente Sopera (Ledesma, La Rioja), Barranco Sopirón (Fanlo, Huesca), Sopiedra (Concejo de Piloña, Asturias), Soperuny (Cornudella de Valira, Lérida).

4.1.10. Lat. podiu: Solopueyo (Bentué, Huesca), Fuente Sopuy (Arén, Huesca), etc.

4.1.11. Rom. sierra: Solasierra (Ayer, Asturias), Susierra (Cangas de Onis, Asturias).

\footnotetext{
${ }^{32} \mathrm{La}$ imagen toponimica, por supuesto, está presente por doquier. En la toponimia española de lengua vasca son frecuentes casos como Altube, Aldabe, Azpe, Azpea, de *aldu, altu, 'alto' o aitz, 'peña' y-be(h)e, 'suelo, parte inferior', etc.
} 
4.2. Existiendo esta serie toponímica, es de esperar que también existan topónimos formados de la misma manera a partir de nuestro término, lat. lumba, lumbu y derivados. Efectivamente, aunque no en abundancia, no faltan los ejemplos: Solaslomas (Santibáñez de la Peña, Palencia), Solomillo (Castil de Vela, Población de Cerrato, Villaprovedo, los tres en Palencia), Solambano (Santas Martas, León), etc. Con cierta seguridad debe entrar también aquí La Sodomilla (Villaprovedo, Palencia), en donde una asociación de etimología popular con Sodoma y la vecindad de los fonemas $/ \mathrm{d} / \mathrm{y}$ /1/ ha alterado un más lógico Solomilla ${ }^{33}$.

4.3. En este orden de cosas parece que podría ser incluido también aquí el conocido topónimo alcarreño Salmerón, de tanta extensión antroponímica ${ }^{34}$. Para que ello fuera así debemos partir de *so-lomerón, con una formación en -on a partir de lomero ${ }^{35}$ disimilación de $/ \mathrm{o} /$ en $/ \mathrm{a} /$, tal y como hemos podido ver con seguridad en muchos de los topónimos derivados de lomo y loma que hemos estudiado, y sincopa de /o/: *solomerón $>{ }^{*}$ salomerón $>$ salmerón. La comparación del topónimo alcarreño con una serie relativamente amplia nos puede proporcionar otra vez luz sobre su origen: Prado Salmero (Matute, La Rioja), Salmarón (Castrillo de Onielo, Palencia), sería muy semejante al toponimo alcarreño, diferenciándose tan sólo en que el derivado sería lomar, no lomero: *Solomarón > *Salomarón> Salmarón, mientras que Salmeronas (Dueñas, Palencia) nos ofrecería una forma en todo igual, pero en femenino plural. No se puede excluir con todo en este último ejemplo la posibilidad de que se trate de un uso antroponímico, feminizado secundariamente, lo que es frecuente. La viabilidad de la evolución de la sílaba inicial de sol- a salcreemos que puede juzgarse posible a partir de ejemplos del tipo Los Salmirones (Briones, La Rioja) ${ }^{36}$ comparado con Gallegos de Solmirón (Salamanca),

\footnotetext{
33 Es éste, por supuesto, el origen del común solomillo en su acepción cámica.

34 Pueden verse algunas otras hipótesis, que estimamos poco verosímiles, en E. Monge Molinero, op.cit., pág. 144 y J. A. Ranz Yubero, op. cit., pág. 229. Nótese que en la primera documentación de este topónimo, en el Cronicón de Sampiro, se le denomina como Salmerón de Suso. Esta amplia utilización antroponímica hace dificil precisar si otros topónimos Salmerón que encontramos un poco por todas partes son topónimos iguales al alcarreño o meros antropónimos en utilización posterior toponímica (asi, por ejemplo, Barnanco Salmerón, Cabra de Santo Cristo, Jaén, Salmerón, Bermar, Jaén, Fuente de Salmerón, Bujalance, Córdoba, etc.

${ }^{35}$ Nótese que *lomerón sería en todo paralelo a otros casos muy semejantes como panderón, de pando, de significado muy cercano. Así, Panderón de Moneno (loma de Almodóvar de Campo, Ciudad Real), etc.

${ }^{36}$ Muy interesante a este propósito F. González Bachiller, op. cit., pág. 29, quien explica Prado Salmero y Los Salmirones, entre otros, a partir de lat. salis muria. 'salmuera'. Esta hipótesis, desde luego verosimil para algunos de los topónimos estudiados, exige necesariamente monoptongación $/$ we/ $>/ \mathrm{e} /$ en Salmero y evolución posterior de $/ \mathrm{e} / \mathrm{a} / \mathrm{i} /$ en Salmirones. Omite, sin embargo, González Bachiller toda referencia a salma, voz presente, como hemos señalado, en la toponimia riojana con seguridad. Nótese, al margen de ello, la presencia de
} 
- Salmercado (San Cebrián de Mudá, Palencia), que parece ser *so el mercado, etc. El término lomero o sus variantes menos evolucionadas lombero, lombeiro aparece en ejemplos del tipo Lomero (Nalda, Viguera, ambos en La Rioja), Lombero (El Pueyo de Fañanás, Huesca), Camino de Lomeros (Albero Alto, Huesca), Lombeira (Salvaterra, Pontevedra), El Lomero (El Cerro de Andévalo, Cortegana, ambos en Huelva), Lomero Alto (Puebla de Guzmán, Huelva), Lomerón Alto (Ródenas, Teruel), Lombera (Rasines, Cantabria), Llumbera (Ruiloba, Cantabria), Lomero (Mazarrón, Murcia), etc. Es un dato muy importante aqui el hecho de que el topónimo valenciano precatalán Llombai (Valencia), Llombai de Gallinera (Alicante) muestra por un lado la evolución semántica de 'lomo' a 'colina', en principio desconocida del conjunto de la lengua catalana, y por otro la formación en -ariu *lumbariu ${ }^{37}$. Como no podia ser de otra manera, otra vez hay ejemplos de topónimos con /// deglutinada, como Fuente de los Homeros (San Martín del Pimpollar, Ávila) ${ }^{38}$ o a partir de la formación en -on, Peña Merón (Villatuelda, Burgos), que, como su propio nombre casi tautológico indica, designa un cerro, de $931 \mathrm{~m}$. de altura. Puede concluirse, pues, de lo señalado hasta aquí, que, aun distando de ser segura, la hipótesis parece verosímil. El examen del lugar concreto que nos ocupa, Salmerón, no está en contradicción con esta hipótesis, pues efectivamente la villa se asienta a los pies de lomas o colinas claramente visibles.

\footnotetext{
Almirones fuera de La Rioja, en lugares como Murcia, en los que uла monoptongación /we/ $>/ \mathrm{e} / \mathrm{y}$ posterior evolución a /i/ parece arriesgada. La realidad es que en Los Salmirones el análisis es muy dificit, pues podemos bien hallarnos ante un real Los Almirones, con aglutinación de /s/ del plural del artículo. En ese caso Almirón podría ser analizada muy bien como *Al(to)mirón, muy semejante al conocido tipo Altamira.

${ }^{37}$ La toponimia valenciana muestra otros muchos casos semejantes, todos ellos a lo que parece precatalanes. Así, Llombo (Ontinyent, Margalida, Benissoda), Llombell (Quatretondeta), sobre todo Els Llombers (Calp, Alicante). Para detalles sobre la cuestión, J. Coromines, Onomasticon Cataloniae, (OC), Barcelona, Curial Edicions Catalanes, 8 vol., 1989-1997, vol. 5 , págs. 93-94, F. de B. Moll, Diccionari català-valencià-balear (DCVB), Palma de Mallorca, Editorial Moli, 10 vol., 1993, vol. 7, pág. 46.

${ }^{38}$ Puede ser de utilidad aquí comparar La Collada del Omero ( $\mathrm{V}$ los montes de Morgoveio) en el Libro de Monteria de Alfonso XI. El dato procede del utilisimo libro de S. Ruhstalter, Materiales para la lexicología histórica. Estudio y repertorio alfabético de las formas léxicas toponímicas contenidas en el "Libro de Montería" de Alfonso XI. Tübingen, Max Niemeyer, 1995. Señala con evidente acierto Ruhstaller, pág. 19, que la variante de este topónimo El Onbro indica una forma vulgar *ómero, aún sin sírcopa de vocal interior. Se trata claramente otsa vez de una metáfora oronimica. Esta interpretación parece muy razonable para este topónimo, pero no debe ser aplicada en principio a los topónimos que nos ocupan, en donde la acentración es llana. Aún más complicadas las cosas, no se nos escapa que cabe aquí otra interpretación, a nuestro juicio también muy plausible. Cabe, en efecto, que se haya deglutínado /s/ injcial con articulo ptural antepuesto: Fuentes de los someros > Fuente de los omeros. Es someto adjetivo frecuente en la toponimia española, del tipo Somera (Andújar, Jaén) o muy semjante a nuestro topónimo abulense Fuente de la somera (El Vallecillo, Teruel), etc. Puede ser relevante la unión de soma. somera a loma en Loma Somena (Valderredible, Cantabria), Soma Lo$m a$ (Las Rozas, Cantabria), Somalomba (Abia de las Torres, Palencia), etc.
} 
4.4. Con todo, no se puede hurtar de manera alguna en una investigación que se quiere rigurosa que otra posibilidad de interpretar Salmerón parece abierta. La razón por la que hemos incluido aquí las dos es que no sabriamos inclinarnos de una manera sincera por ninguna de ellas de una forma decidida y porque se da la circunstancia de que la segunda posibilidad, aun siendo radicalmente distinta de la primera, otorgaría al topónimo un significado sin embargo muy semejante.

En efecto, es bien conocida la voz latina sagma, préstamo técnico y popular del gr. ságma, deverbativo de sátto. Su significado es 'silla de montar, albarda, carga suspendida' y por extensión 'bestia de carga'. Se trata de un término panromance a partir de unas formas sauma, sagma, salma, la última de las cuales figura ya en $\mathrm{S}$. Isidoro Etym. $\mathrm{XX}, 26,5$ sagma, quae corrupte uulgo sauma dicitur...Es éste naturalmente el origen del esp. sal$m a$, que el DRAE da como propio de La Rioja y Soria, y del más común enjalma, definido por el DRAE como "especie de aparejo de bestia de carga, como una albardilla ligera». Este vocablo parece deverbativo de enjalmar, 'poner la jalma', mientras que el tratamiento de /s/ inicial parece acusar un origen mozárabe. Así las cosas, pues, topónimos del tipo La Salma (Soria), Salmas (Lorca, Murcia), Salma de Camarón (Sástago, Zaragoza), La Salmilla (Calahorra, La Rioja) parecen mostrar una aplicación toponímica del término, que es en última instancia, y ello es de vital importancia en nuestro trabajo, la misma que la vista a propósito de 'lomo' ${ }^{39}$. Se ha comparado un cerro o varios, de figura ondulada y suave, con la silla o la albarda que se pone sobre el animal. La imagen reaparece un poco por todas partes, expresada también con los otros vocablos del mismo campo semántico: La Albardilla (Bustarviejo, Madrid), La Albarda (Calasparra, Lorca, ambos en Murcia), El Albardero (Fortuna, Murcia), Albardero (Aldehuela, Teruel), La Albardera (Feria, Badajoz), Cabezo La Albarda (Puebla de Guzmán, Huelva), Los Albardones (Zalamea la Real, Huelva), Charca de las Albardillas (Bohoyo, Ávila), Alforja (Campillo, Murcia), Las Alforjas (Cartagena, Murcia), Las Alforjillas (Autillo de Campos, Palencia), Alforja (Tarragona) ${ }^{40}$, Alforgetas (Lanaja, Huesca), etc. Nuestro topónimo Salmerón

\footnotetext{
${ }^{39}$ Que es asi lo demuestra de alguna manera el hecho de que puede emplear también la misma palabra lomillo para la designación del aparejo. Así, lomillos: «aparejo con dos almohadillas largas y estrechas rellenas de paja, que se colocan sobre el sudaor y bajo la albarda o el aparejo», F. Gómez Martín, Vocabulario del nomeste murciano, Murcia, Editora Regional de Murcia, 1991, pág. 261.

${ }^{40}$ Sorprende aqui Coromines atribuyendo al topónimo un origen distinto del vocabio común catalán alforja, usualmente sólo plural alforges por razón del significado de la palabra. Como hemos señalado un uso toponímico de alforja es común y muy frecuente. Deberian añadirse aquí al menos algunos casos de sillas y quizá de sillero de la toponimia española, del tipo La Silleta (cerro de Mazarrón, Murcia), Las Silletas (cerro de Alhama, Murcia),
} 
podría ser entendido perfectamente de esta manera, si admitimos la posibilidad de un derivado en -ero prácticamente sinónimo de la forma base, lo que por otra parte sucedía con lomo/lomero y tantos otros, y un diminutivo. Ciertamente el término sagmarius existió en latín, pero con el significado de 'animal de carga', y parece ser el origen del cat. somera, de ese significado, del fr. sommier, etc., pero en nuestro caso se trataría propiamente de un derivado románico. A mayor abundamiento, tenemos constancia de la existencia de salmera y de enjalmero, pero con evoluciones léxicas alejadas de la precisa para explicar Salmerón ${ }^{41}$. Esta hipótesis de explicación de Salmerón presenta frente a la hipótesis *sol(o)merón indudables ventajas de orden fonético, y es muy razonable para dar cuenta de topónimos como el ya citado Prado Salmero u otro como Las Salmeras (Mazarrón, Murcia), Salmerina (Tabuenca, Zaragoza), quizá también formas con /s/ inicial aparentemente deglutinada del tipo Peña de las Almeras (Cubiliero de la Sierra, Guadalajara), Los Almerines (mun. de Badajoz), pero no debemos obviar el hecho de que no es suficiente para explicar sin más topónimos del tipo Salmarón, sobre todo si los comparamos con Marón, Marona, etc.

Como quiera que sea, nos parece que es notable el hecho de que se elija una u otra explicación, ambas a nuestro juicio igualmente plausibles en nuestro estado de conocimiento de los hechos, el significado no varía mucho. En el primero de los casos, el significado sería 'bajo la lomera', en el segundo simplemente 'la albarda', esto es, 'la loma'.

4.5. Parece razonable afirmar que la veracidad de las hipótesis propuestas puede ser comprobada en alguna medida si la naturaleza orográfica de los lugares denominados con los topónimos estudiados está de acuerdo con los significados atribuidos. Naturalmente, esta posibilidad de verificación no se da siempre en toponimia, pues, como es sabido, en el curso de centenares de años, a veces millares, la naturaleza puede haber sido cambiada en grado muy elevado. No parece, con todo, el caso nuestro, pues en principio una loma o elevación debe perdurar hasta la actualidad. En la medida de nuestras posibilidades hemos verificado la mayor parte de los topónimos estudiados ${ }^{42}$,

Cabezo Sillado (Mazarrón, Murcia), Silleros (Villota del Páramo, Palencia), Barranco del Sillo de Fuentes (Fuentes de León, Badajoz), Barranco de la Silla (Valdepeñas de la Sierra, Guadalajara), etc.

${ }^{41}$ EJ DRAE trae aguja salmera como sinónimo de aguja de enjalmar y enjalmero como «el que hace o vende enjalmas». Nótese más arriba El Albardero, que podría no ser nombre de oficio.

${ }^{42} \mathrm{Se}$ ha hecho mediante consulta de mapas topográficos escala 1:50.000 y 1:25.000. Debe resaltarse aquí que no siempre los topónimos citados como existentes en los distintos repertotios de nombres geográficos o en estudios toponimicos especializados aparecen en estos mapas, que omiten muchos topónimos. 
aunque no todos, y creemos que se puede afirmar con rigor que en la mayor parte de los casos la conformación del terreno parece no estar en contradicción con nuestras hipótesis. Hay casos de todo tipo que no podemos tratar aquí con detalle, pero en general los topónimos del tipo Manotera, Maroteras están asociados con la presencia de elevaciones del terreno, a menudo propiamente hablando lomas. En el caso de Maroto las cosas son mucho más complicadas, pues es evidente que desde fecha temprana y con relativa extensión ha sido utilizado como designación antroponímica. En este orden de cosas, hay topónimos del tipo Silo de Maroto en los que Maroto es sencillamente antropónimo. Distinguir entre topónimos auténticos y antropónimos de origen toponímico utilizados como topónimos es sencillamente inviable. Somos conscientes, con todo, que solamente estudios de detalle de pequeñas comarcas podrán poner en mayor o menor evidencia la veracidad o incorrección de nuestros análisis para éste o aquel topónimo.

\section{ReCAPITULACIÓN Y CONCLUSIONES}

Creemos que como recapitulación y conclusión fundamentales es razonable sostener que existe un complejo toponímico relativamente abundante y extendido de nombres formados a partir de la unión de lomo/a y derivados del tipo lomar, lomero, lomana a formaciones adjetivales que indican altura como oto, ota, otero, etc. A menudo se ha producido la deglutinación de un falso artículo y algunos detalles fonéticos que han ocultado estos origenes. En otros casos se ha antepuesto a las formas citadas la preposición so- para indicar 'bajo la loma', lo que también aparece repetidas veces con otros términos del mismo campo semántico como 'peña', 'sierra', 'cueto', etc. En un caso concreto, el del macrotopónimo Salmerón, es difícil, si no imposible, precisar si estamos ante un caso más de anteposición de dicha preposición o ante un derivado de salma, 'albarda', que ha sido utilizado metafóricamente para la expresión de 'loma', empleando la misma imagen que hallamos precisamente en 'loma' $o$, aún mejor, en 'albarda', en 'alforja', quizá también en algunos casos de 'silla'. Creemos que, como indicábamos al comienzo de esta nota, el cotejo de series toponímicas amplias ha permitido arrojar alguna luz sobre estos topónimos y ha permitido proponer hipótesis que se nos antojan verosímiles. Es evidente que no en todos los casos citados se trata de topónimos, pues parecen existir casos evidentes de los que la utilización antroponímica posterior puede dar cuenta satisfactoriamente. En buena medida es dificil precisar los ejemplos de to uno y de lo otro, pero particularmente en el caso de Maroto hay una utilización antroponímica amplia y extendida, que dio lugar a la hipótesis, que 
hemos juzgado equivocada, de Coromines. Somos conscientes, naturalmente, de que algunos de los ejemplos aducidos pueden ser analizados de otras maneras y de que es probable que algunos de ellos estén, pura y sencillamente, equivocados. La impugnación de este o aquel ejemplo, razonable, no supone en sí en modo alguno la impugnación del conjunto de la hipótesis que se sustenta en decenas de ejemplos tan claros e innegables que dificilmente admiten otra explicación más verosímil. En un campo tan oscuro y complejo como el que hemos analizado no puede ser nunca de otra manera, lo que, por otra parte, sucede en otros muchos estudios lingüísticos, aunque no siempre se advierte. 


\begin{tabular}{|c|c|c|c|c|c|c|c|c|c|c|c|}
\hline \multicolumn{2}{|c|}{ Sustantivo base } & \multicolumn{2}{|c|}{$\begin{array}{l}\text { Derivados } \\
\text { en -ar, -ero }\end{array}$} & \multicolumn{2}{|c|}{$\begin{array}{l}\text { Derivados en } \\
\text {-ana, -ano, -an }\end{array}$} & \multicolumn{2}{|c|}{$\begin{array}{l}\text { Derivados en } \\
-a l\end{array}$} & \multicolumn{2}{|c|}{$\begin{array}{l}\text { Derivado en } \\
\text {-ada }\end{array}$} & \multicolumn{2}{|c|}{$\begin{array}{l}\text { Derivado en } \\
\text {-ato }\end{array}$} \\
\hline $\begin{array}{l}\text { Forma } \\
\text { plena }\end{array}$ & $\begin{array}{l}\text { Forma con } \\
\text { deglutin. } \\
\text { y/o aféresis }\end{array}$ & $\begin{array}{l}\text { Forma } \\
\text { plena }\end{array}$ & $\begin{array}{l}\text { Forma con } \\
\text { deglutin. } \\
\text { y/o aféresis }\end{array}$ & $\begin{array}{l}\text { Forma } \\
\text { plenta }\end{array}$ & $\begin{array}{l}\text { Forma con } \\
\text { deglutin. } \\
\text { y/o aféresis }\end{array}$ & $\begin{array}{l}\text { Forria } \\
\text { plena }\end{array}$ & $\begin{array}{l}\text { Forma con } \\
\text { deglutin. } \\
\text { y/o aféresis }\end{array}$ & $\begin{array}{l}\text { Forma } \\
\text { plena }\end{array}$ & $\begin{array}{l}\text { Forma con } \\
\text { deglutin. } \\
\text { y/o aféresis }\end{array}$ & $\begin{array}{l}\text { Forma } \\
\text { plena }\end{array}$ & $\begin{array}{l}\text { Forma con } \\
\text { deglutin. } \\
\text { y/o aféresis }\end{array}$ \\
\hline $\begin{array}{l}\text { Lombo } \\
\text { Lomba } \\
\text { Lomo } \\
\text { Loma }\end{array}$ & $\begin{array}{l}\text { Hombo } \\
\text { Ombo } \\
\text { Omba } \\
\text { Omo }\end{array}$ & $\begin{array}{l}\text { Lomar } \\
\text { Lomena } \\
\text { Lomero } \\
\text { Lomerón }\end{array}$ & $\begin{array}{l}\text { Marmayor } \\
\text { Maranchón } \\
\text { Homero } \\
\text { Omero } \\
\text { Merón }\end{array}$ & $\begin{array}{l}\text { Lombana } \\
\text { Lombano } \\
\text { Lomana } \\
\text { Lomano } \\
\text { Loman }\end{array}$ & $\begin{array}{l}\text { Man, } \\
\text { Humanes }\end{array}$ & Lomal & & $\begin{array}{l}\text { Lomada } \\
\text { Lomado }\end{array}$ & $\begin{array}{l}\text { Omada } \\
\text { Omado }\end{array}$ & Lombato & $\begin{array}{l}\text { Omato } \\
\text { Cerro de } \\
\text { Amatos }\end{array}$ \\
\hline \multicolumn{12}{|c|}{ Unión del sustantivo al adjetivo afto, oto, otero en la formación del compuesto toponímico } \\
\hline $\begin{array}{l}\text { Lomo Alto } \\
\text { Loma Alta }\end{array}$ & & $\begin{array}{l}\text { *Lomar } \\
\text { oto } \\
\text { "Lomar } \\
\text { otera }\end{array}$ & $\begin{array}{l}\text { La } \\
\text { Maroto } \\
\text { La } \\
\text { Marota }\end{array}$ & $\begin{array}{l}\text { *Lomana } \\
\text { ota } \\
\text { "Lomana } \\
\text { otera }\end{array}$ & $\begin{array}{l}\text { Manauta } \\
\text { (La) Manota } \\
\text { (La) } \\
\text { Manotera }\end{array}$ & $\begin{array}{l}\text { *Lomal } \\
\text { ota/o } \\
\text { "Lomal } \\
\text { otem } / a\end{array}$ & $\begin{array}{l}\text { (La) } \\
\text { Malota } \\
\text { (La) } \\
\text { Malotera }\end{array}$ & & & & \\
\hline \multicolumn{12}{|c|}{ Distintas formaciones sufijadas de diminutivos } \\
\hline & $\begin{array}{l}\text { Ombillo } \\
\text { Umbilla } \\
\text { Homillo } \\
\text { Humiello } \\
\text { Omillas } \\
\text { El Homillo, }\end{array}$ & $\begin{array}{l}\text { Lombarejo } \\
\text { Lombarin } \\
\text { Lomarejo } \\
\text { Lomarita } \\
\text { Lomarino } \\
\text { Lomarin } \\
\text { Lomarón } \\
\text { Lomarona }\end{array}$ & $\begin{array}{l}\text { Unarino } \\
\text { Marón } \\
\text { Marona } \\
\text { Marotilla } \\
\text { Marotón }\end{array}$ & $\begin{array}{l}\text { Lombani- } \\
\text { lla } \\
\text { Lombanico } \\
\text { Lomanillo } \\
\text { Lomaniel }\end{array}$ & $\begin{array}{l}\text { Humba- } \\
\text { nillo } \\
\text { Mano- } \\
\text { terillo } \\
\text { Maniel }\end{array}$ & & & Lomadilla & Omadillas & & \\
\hline
\end{tabular}




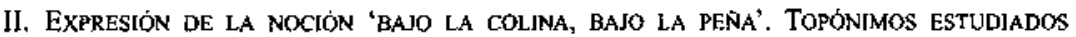

\begin{tabular}{|l|l|}
\hline collado & Sulcollao Bringales, Socollao \\
\hline cueto & Allo de Zocueto, El Sucuetu \\
\hline lastra & Solalastra \\
\hline \hline loma & $\begin{array}{l}\text { Solaslomas, Solomillo, Solambana, Solamanilla, La Sodomilla, } \\
\text { Salmerón, Prado Salmero, Salmeronas, Salmarón }\end{array}$ \\
\hline \hline losa & Solalosa, Solallosica \\
\hline mira, mirón & Gallegos de Solmirón \\
\hline monte & Solmonte, Somonte, Salmonte \\
\hline otero, alto & Solotero, Solutero, Sotal \\
\hline peña & $\begin{array}{l}\text { Sopeña, Solapeña, Solapenilla, Sopeñillas, Sopena, Sopeñano, Sulapena, } \\
\text { Xupena, Salapeña }\end{array}$ \\
\hline piedra & Sopeira, Fuente Sopera, Barranco Sopirón, Sopiedra, Sopenuny \\
\hline poyo, pueyo & Solopueyo, Fuente Sopuy \\
\hline sierra & Solasierra, Susierra \\
\hline
\end{tabular}

III. EXPREsión de La NOCión 'LOMA' mediante la imagen 'Albarda'. TOPónimos citados

\begin{tabular}{|c|c|}
\hline albarda & $\begin{array}{l}\text { La Albardilla, La Albarda, Garganta de la Albardilla, El Albardero, } \\
\text { La Albardera, Albardero. Los Albardones, Cabezo La Albarda. Charca } \\
\text { de las Albardillas }\end{array}$ \\
\hline alforja & Alforja, Las Alforjas, Las Alforjillas, Alforgetas \\
\hline salma & $\begin{array}{l}\text { La Salma, Salmas, Prado Salmero, Las Salmeras, Salmerón, Salma de } \\
\text { Camarón. Salmerina, La Salmilla, Peña de las Almeras, Los Almerines }\end{array}$ \\
\hline silla & $\begin{array}{l}\text { Cabezo Sillado, Silleros, La Silleta, Barranco del Sillo de Fuentes, } \\
\text { Barranco de la Silla }\end{array}$ \\
\hline
\end{tabular}

